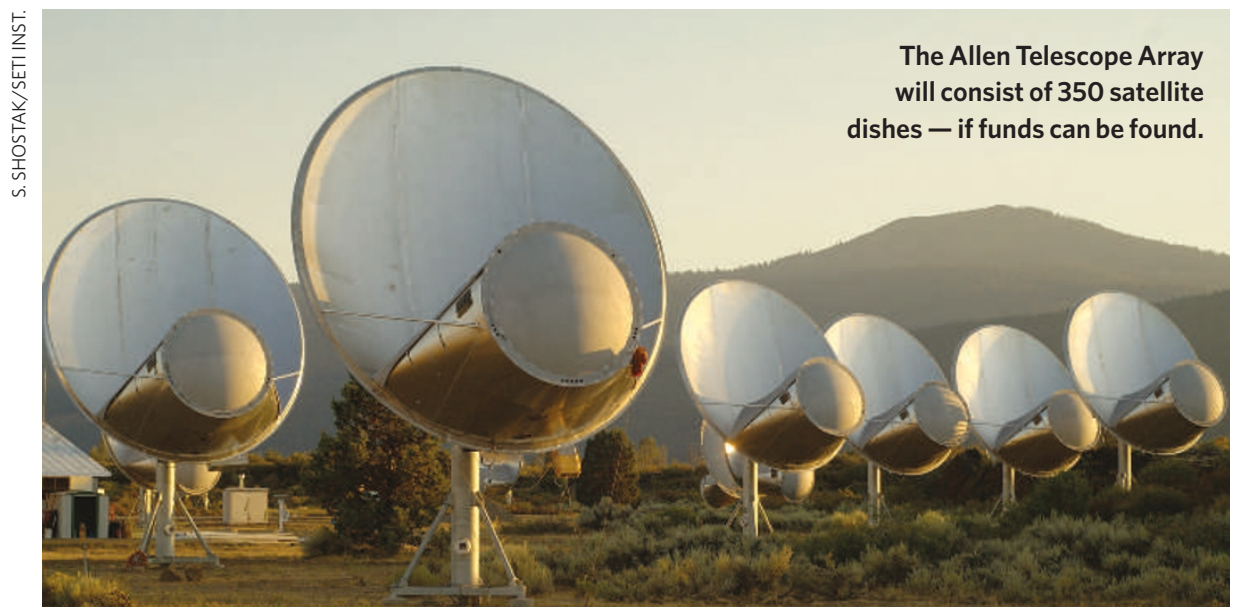

\title{
Search for alien signals stalls for want of cash
}

An ambitious radio array project that will join the search for extraterrestrial intelligence (SETI) is running into money problems.

Construction of the Allen Telescope Array, named after its chief benefactor, Microsoft co-founder and billionaire Paul Allen, will halt at the end of this year unless further funding is found. Allen is currently withholding millions because the project has failed to recruit other donors.

"Down here in the trenches it's really terribly worrisome," says Jill Tarter, director of the privately funded SETI Institute in Mountain View, California, which is developing the project.

The array, which is being built at Hat Creek Radio Observatory in California, was conceived in the late 1990s as a cheap way to search for extraterrestrial radio transmissions. For about \$25 million, researchers believed they could build a radio telescope with 350 commercially available satellite dishes. The price went up to $\$ 43$ million in 2003, when scientists decided to upgrade the dishes and other components, allowing the array to do radio astronomy as well as searching for alien signals.

In 2000, Allen gave the project's research budget \$11.5 million. He pledged \$13.5 million more for construction in 2003 - but the money was contingent on the SETI Institute raising another $\$ 16$ million in private funding (see Nature 428, 358; 2004).

To date, the institute has raised less than $\$ 9$ million. Allen is withholding \$3.85 million until the institute can "meet its contractual obligations", says Jason Hunke, a spokesman for the Paul G. Allen Family Foundation, based in Seattle, Washington.

Astronomers often use private funding for telescopes, and almost as often find themselves in tight spots. Researchers at the California Institute of Technology (Caltech) in Pasadena nearly abandoned the second of the huge Keck telescopes before NASA provided a multi-million-dollar bailout.

And the Sloan Digital Sky Survey, a \$70million map of the sky, had to beg and borrow from collaborators, says James Gunn, a founder of the project at Princeton University in New Jersey. "We were on the edge of financial disaster
ntinuously," he says, adding that more or less continuously," he says, adding
the project has since repaid most of its debts.

With the funds currently available, the Allen Telescope Array will have just 42 of its planned 350 dishes up by the end of the year, according to Leo Blitz, an astronomer at the University of California, Berkeley, the project's major collaborator. This will still be enough to start doing science, he adds.

But the full array would be much better, says Shri Kulkarni, a radio astronomer at Caltech. The more expensive array would deliver high-resolution, wide-angle images of the sky relatively cheaply, he says.

And it would be an important proof-ofprinciple for future radio observatories, such as the international Square Kilometre Array. If the Allen array didn't move forward, Kulkarni says, "it would be a pity in almost every way I could think of".

Geoff Brumfiel 